\title{
EFETIVIDADE DO DIREITO À EDUCAÇÃO: POSITIVAÇÃO E JUSTICIABILIDADE
}

\section{THE EFFECTIVENESS OF THE RIGHT TO EDUCATION: POSITIVITY AND JUSTICIABILITY}

\author{
${ }^{1}$ Rodrigo Batista Coelho \\ ${ }^{2}$ José Antonio Remédio
}

\section{RESUMO}

A contemporaneidade dos direitos humanos é marcada pela conjugação do valor liberdade e igualdade, o que implica reconhecer que a plena realização dos direitos civis e políticos está condicionada à efetivação dos direitos sociais, com destaque para o direito à educação. Assim, o presente artigo objetiva destacar os principais desafios e os mecanismos para a efetivação do direito humano à educação, haja vista a tendência de esvaziamento do espírito solidarístico dos direitos sociais, o que se fará por meio da contextualização histórica e da análise de casos concretos, com utilização de pesquisa analítica e descritiva.

Palavras-Chaves: Direitos Fundamentais; Efetivação dos Direitos Fundamentais; Direitos Sociais; Direito à Educação; Controle Judicial.

\begin{abstract}
The contemporaneity of the human rights is marked by the combination of the values of freedom and equality, which implies recognizing that the full realization of civil and political rights is conditioned to the implementation of social rights, especially the right to education. Thus, this article aims to highlight the main challenges and the mechanisms for the implementation of the human right to education, given the tendency to empty the spirit of solidarity of social rights, which will be done through the historical context and analysis of specific cases, using analytical and descriptive research.
\end{abstract}

Keywords: Fundamental Rights; Implementation of Fundamental Rights; Social Rights; Right to Education; Judicial Control.

\footnotetext{
${ }^{1}$ Mestre em Direito pela Universidade Metodista de Piracicaba - UNIMEP, São Paulo, (Brasil). Professor de Direito Constitucional e Direitos Humanos da Graduação da UNIMEP. E-mail: rodrigobcoelho@ hotmail.com

2 Doutor em Direito pela Pontifícia Universidade Católica - PUC, São Paulo, (Brasil). Professor do Mestrado da Universidade Metodista de Piracicaba - UNIMEP. Professor de Graduação do Centro Universitário Adventista de São Paulo - UNASP. E-mail: jaremedio@yahoo.com.br
} 


\section{INTRODUÇÃO}

“Educação, palavra imensa (...)”, já dizia Cecília Meireles (2001, p. 65), poetisa e educadora.

Há muito se diz, entre outras frases, que "o Brasil precisa investir mais em educação", "a educação é determinante para o progresso de uma nação" e "o Brasil é a pátria educadora".

Ocorre, porém, que por mais que se tenha por incontroverso que a educação é um direito fundamental por excelência, a realidade demonstra que a efetivação desse relevante direito ainda está muito aquém do esperado, notadamente se considerado o momento atual, onde a retórica educacional, como lema inclusive de vários programas de governo, não vem acompanhada de estratégias de positivação que, de fato, façam da educação uma prioridade como política de governo.

Ora, a educação está intrinsecamente ligada à dignidade da pessoa humana, tomada como fundamento da República Federativa do Brasil (art. $1^{\circ}$, III, da Constituição Federal) e princípio informador de toda a ordem jurídica, conformando a ação de todos os poderes constituídos.

Isso porque não é crível conceber que o indivíduo que tenha sido apartado do processo educacional possa desenvolver, no contexto social, todas as suas potencialidades, especialmente se considerado o caráter instrumental dos direitos sociais (direitos-meio), "isto é, direitos cuja principal função é assegurar que toda pessoa tenha condições de gozar os direitos individuais de primeira geração" (BUCCI, 2006. p. 3). Nesse sentido, os direitos fundamentais sociais "garantem a liberdade fática" (QUEIROZ, 2006, p. 49).

Não é por outra razão que Ingo Wolfgang Sarlet (2011, p. 101) correlaciona a dignidade da pessoa humana com os direitos fundamentais, ao evidenciar que

os direitos fundamentais constituem - ainda que com intensidade variável explicitações da dignidade da pessoa humana, por via de consequência e, ao menos em princípio (já que exceções são admissíveis, consoante já frisado), em cada direitos fundamental se faz presente um conteúdo ou, pelo menos, alguma projeção da dignidade da pessoa humana.

No caso, a projeção da dignidade humana no direito fundamental à educação revela-se ainda mais acentuada, dadas as peculiaridades desse direito, que o tornam tão essencial ao pleno exercício da cidadania. 
Entretanto, a realidade brasileira é ainda marcada por desafios no que se relaciona à efetividade desse direito, o que fica claro diante dos índices de analfabetismo, do descumprimento de metas educacionais assumidas perante organismos internacionais e da queda do Brasil no ranking do Índice de Desenvolvimento Humano (IDH) apurado pela ONU, que coloca o país, em comparação com os demais analisados, na $75^{\mathrm{a}}$ posição, conforme o Relatório de Desenvolvimento Humano do ano de 2015 (ONU, 2015).

Nesse sentido, e por mais que a educação seja tema recorrente de palestras, artigos e seminários, sempre será necessário reafirmar sua fundamentalidade e repensar as estratégias de positivação desse direito fundamental, seja, precipuamente, por meio da eleição de políticas públicas adequadas, seja, em última análise, por meio dos instrumentos jurídicos adequados à sua concretização, tanto individualmente, através da proteção do direito subjetivo, quanto coletivamente, por intermédio da realização das políticas públicas.

À vista dessas considerações iniciais, o presente trabalho, por meio da contextualização histórica e da análise de casos concretos, com utilização de pesquisa analítica e descritiva, objetiva reforçar a relevância do direito à educação no contexto das opções de governo, notadamente em períodos em que a agenda do país passa a ser elaborada em função do discurso da "crise econômica", com possíveis impactos para os direitos sociais, por demandarem ações prestacionais do Estado para serem realizados.

Nessa perspectiva, é imperiosa a adoção de estratégias de positivação do direito à educação que realcem sua fundamentalidade e que o salvaguardem das investidas liberais que, por vezes, impõem a diminuição de gastos públicos em áreas sociais e, com isso, promovem o esvaziamento solidarístico ${ }^{3}$ desses direitos indispensáveis ao exercício da cidadania.

\section{OS DIREITOS HUMANOS ECONÔMICOS, SOCIAIS E CULTURAIS NA CONTEMPORANEIDADE}

O tratamento dispensado aos direitos humanos é, na contemporaneidade, marcado pela reafirmação da inclusão dos direitos sociais, econômicos e culturais, oriundos da luta do proletariado, no rol de direitos inerentes à condição de pessoa. A tônica dada a esses direitos,

\footnotetext{
${ }^{3}$ Em crítica ao esvaziamento do Estado de Bem-Estar Social, especialmente em períodos de crises econômicas, José Joaquim Gomes Canotilho destaca que o recurso à dignidade da pessoa humana, como princípio fundante da dignidade social da pessoa humana, a depender de prestações sociais a cargo do Estado, estaria sendo relativizado pela jurisprudência portuguesa, apontando para o "'esvaziamento solidarístico'” desta estratégia discursiva do Tribunal Português" (CANOTILHO, 2008, p. 247).
} 
também chamados de $2^{\mathrm{a}}$ geração (ou dimensão), supera a tradicional ideia que restringia os direitos humanos apenas aos direitos civis e políticos (marcantes nas cartas de direitos dos séculos XVIII, XIX e início do século XX).

Foi com a Declaração Universal dos Direitos Humanos de 1948 que, em âmbito global, foram realçadas a universalidade e a indivisibilidade dos direitos humanos, conjugando-se, assim, os valores liberdade e igualdade. Nessa perspectiva, a condição de pessoa é o requisito único e exclusivo para a titularidade de direitos (universalidade), sendo a dignidade humana o fundamento dos direitos humanos. Lado outro, a indivisibilidade realça, pela primeira vez, o catálogo dos direitos civis e políticos conjugado ao catálogo dos direitos econômicos, sociais e culturais, tendo a Declaração Universal pretendido, com isso, combinar "o discurso liberal e o discurso social da cidadania, conjugando o valor da liberdade ao valor da igualdade" (PIOVESAN, 2009, p. 6).

Evidente que não se desconhece, a essa altura, que antes mesmo da Carta das Nações Unidas, a Constituição Mexicana de 1917 e a Constituição de Weimar (1919) haviam positivado em seus textos os direitos econômicos, sociais e culturais, servido essa atitude de referência para tantos outros países.

Ocorre, porém, que é somente após a Segunda Guerra Mundial que ganha maior força, no âmbito da comunidade de nações, a disseminação da conjugação dos valores liberdade e igualdade, sem o que restaria inviabilizada a plena satisfação dos direitos humanos.

Não é por outra razão que, no ano de 1966, na tentativa de conferir maior "juridicização" à Declaração Universal dos Direitos Humanos, é aprovado o Pacto Internacional dos Direitos Econômicos, Sociais e Culturais, o qual estabelece deveres endereçados aos Estados (prestações materiais) com realização progressiva.

Entretanto, somente em 10 de dezembro de 2008 os direitos sociais, econômicos e culturais passaram a contar com o mecanismo de petição individual perante o Comitê de Direitos Econômicos, Sociais e Culturais das Nações Unidas, para apreciação de denúncias de indivíduos, ou grupos de indivíduos, sob alegação de serem vítimas de violações dos preceitos do aludido Pacto, tendo seu Protocolo Facultativo enfrentado a resistência de diversos países desenvolvidos, a exemplo do Reino Unido, EUA, Canadá e Austrália (PIOVESAN, 2013, p. 259).

Como é cediço, os direitos sociais encontram assento no princípio da dignidade humana e trazem consigo o valor igualdade em seu conteúdo. Esses direitos são, no caso 
brasileiro, a tônica do atual Estado Democrático e Social de Direito, inaugurado pela ordem constitucional de 1988.

É sem dúvida em relação aos menos favorecidos que os direitos econômicos, sociais e culturais são mais significativos, porquanto visam a corrigir as desigualdades fáticas, o que corresponde à aplicação do princípio da igualdade material.

A propósito da importância histórica dos direitos sociais (direitos fundamentais de segunda geração) no âmbito dos direitos humanos, Fábio Comparato (2010, p. 66) destaca que:

\begin{abstract}
O reconhecimento dos direitos humanos de caráter econômico e social foi o principal benefício que a humanidade recolheu do movimento socialista, iniciado na primeira metade do século XIX. O titular desses direitos, com efeito, não é o ser humano abstrato, com o qual o capitalismo sempre conviveu maravilhosamente. É o conjunto dos grupos sociais esmagados pela miséria, a doença, a fome e a marginalização. Os socialistas perceberam, desde logo, que esses flagelos sociais não eram cataclismos da natureza nem efeitos necessários da organização racional das atividades econômicas, mas sim verdadeiros dejetos do sistema capitalista de produção, cuja lógica consiste em atribuir aos bens de capital um valor muito superior ao das pessoas.
\end{abstract}

O princípio da igualdade, por sua vez, fundamento para a concretização dos direitos sociais, assenta raízes no Cristianismo primitivo, que carregava consigo a mensagem de libertação do homem, com afirmação da sua dignidade humana, à luz da noção de que os homens seriam criaturas formadas à imagem e semelhança de Deus, o que, por consequência, conduz à ideia de irmandade e igualdade entre os seres humanos (SILVA, 2001, p. 173).

Compreendida a insuficiência dos direitos civis e políticos para a garantia da existência digna, os direitos sociais passam a ser reivindicados no contexto da Revolução Industrial e com a luta do proletariado, porquanto a burguesia, convicta da sua condição de classe social hegemônica, jamais encontrou limites em seu anseio de ampliação da produção e de riquezas.

Invariavelmente, o resultado dessa atomização social, como não poderia deixar de ser, foi a brutal pauperização das massas proletárias, já na primeira metade do século XIX, o que tornou inevitável "suscitar a indignação dos espíritos bem formados e a provocar a indispensável organização da classe trabalhadora” (COMPARATO, 2010, p. 66).

Daí decorre a importância dos direitos econômicos, sociais e culturais na redução das desigualdades materiais, sobretudo porque esses direitos estão intimamente ligados ao 
denominado "mínimo vital", "mínimo de existência condigna", "mínimo existencial” ou "mínimo de sobrevivência", expressões largamente utilizadas no contexto desses direitos.

Nesse ponto, revela-se esclarecedora a definição apresentada por Vidal Serrano Nunes Júnior (2009, p. 70) acerca do "mínimo vital”, segundo o qual ele deve ser "entendido como o dever do Estado, caudatariamente ao princípio da dignidade humana, garantir a todos um 'standard' social mínimo incondicional".

Ingo Wolfgang Sarlet (2006, p. 567), ao fazer alusão à contribuição alemã acerca do tema, observa que o "mínimo vital ou mínimo de sobrevivência", vincula-se à garantia da vida humana, sem necessariamente abarcar as condições para sobrevivência física em condições dignas; ou seja, ter uma vida com certa qualidade.

Relativamente à vinculação entre os direitos sociais consagrados na Constituição Federal de 1988 e o princípio da dignidade da pessoa humana, Sarlet evidencia a impossibilidade de se ignorar essa conexão, que será sempre mais intensa, quanto maior for a importância dos direitos sociais para a efetiva fruição de uma vida digna (SARLET, 2011, p. 114).

Porém, nesse ponto, merece especial destaque o caráter rebus sic stantibus do "mínimo existencial”, em correlação com a dignidade da pessoa humana, vez que seu conteúdo varia no tempo e espaço, obedecendo aos padrões de uma determinada sociedade, servindo de parâmetro dinâmico para a concretização dos direitos fundamentais, sob a óptica do princípio da dignidade da pessoa humana.

A título de exemplo, não se pode conceber que o critério de concretização do direito social ao trabalho, em vigor na década de 1950, seja o mesmo adotado nos dias atuais, marcado pela competitividade do mercado, de que decorre a constante exigência de aprimoramento profissional do indivíduo.

Nessa linha de pensamento, há cinquenta anos a outorga do direito à educação pelo Estado, entendido como direito propulsor da concretização do direito social ao trabalho, poderia resumir-se ao acesso do indivíduo ao ensino fundamental e médio, o que lhe seria suficiente para alçar amplamente quaisquer postos de trabalho e, por consequência, participar da produção das riquezas. Com isso, estaria garantido ao indivíduo um mínimo de inserção social, em suposto respeito à dignidade da pessoa humana.

Por outro lado, hodiernamente o indivíduo é bombardeado pelos processos globalizantes e pelas mudanças de paradigma social (em todos os níveis da vida), o que lhe faz reclamar por novas posturas estatais, capazes de garantir-lhe o mínimo existencial, 
necessário à manutenção da sua dignidade humana. Isto representa, em última análise, a garantia de igualdade de possibilidades, especialmente em um ambiente social marcado pela velocidade das mudanças e pelo aumento das exigências, no qual o conhecimento agregado passa a ter importante papel na emancipação do indivíduo e na fruição de tantos outros direitos.

Na mesma linha de pensar é a abordagem novamente de Ingo Sarlet (2011, p.114), quando sublinha que se impõe o reconhecimento da mutabilidade dos parâmetros para a garantia de uma vida digna. Conforme palavras textuais do pensador mencionado:

as condições de vida e os requisitos para uma vida com dignidade constituam dados variáveis de acordo com cada sociedade e em cada época, o que harmoniza com a já destacada dimensão histórico-cultural da própria dignidade da pessoa humana e, portanto, dos direitos fundamentais (inclusive sociais) que lhes são inerentes.

Não se pode esquivar ao reconhecimento da estreita relação existente entre mínimo existencial, dignidade da pessoa humana e direitos fundamentais sociais, sendo que os últimos “constituem obrigações de prestação 'positivas' cuja satisfação consiste num 'facere', uma 'ação positiva' a cargo dos poderes públicos” (QUEIROZ, 2006, p. 25).

Especificamente no tocante à educação, importante destacar que o denominado mínimo existencial não se resume ao mínimo vital, pois seu conteúdo abrange também as condições socioculturais que, para além da questão da mera sobrevivência, asseguram ao indivíduo um mínimo de inserção na vida social.

Nesse contexto, é evidente que, dentre os direitos prioritários, está o direito à educação. No espaço público, onde se travam as relações comerciais, profissionais, trabalhistas, assim como onde se exerce a cidadania, a ausência de educação, como fator de socialização de conhecimentos, valores e outros requisitos de integração social, em regra, relega o indivíduo a posições subalternas (BRASIL, 2010).

Contudo, não raras vezes a concretização dos direitos sociais revela-se dificultada, haja vista a alegada existência de limites orçamentários por parte dos Estados, os quais, normalmente, acabam por invocar a conhecida doutrina da "reserva do possível” como escusa às lacunas nessa espécie de direito fundamental.

Não é por outro motivo que Konrad Hesse (2009, p. 46) afirma haver certa fragilidade intrínseca à natureza dos direitos sociais, no que diz respeito ao seu estatuto constitucional, visto que, em seu entender, estes não consolidam direitos subjetivos (que geram possibilidade 
de reparação perante o Estado), mas apenas direitos que são realizados através de "tarefas de Estado", programas de objetivos sujeitos a amplas margens legislativas e políticas de configuração.

Embora passível de questionamentos, Hesse sustenta que a cláusula de Estado social de Direito não fundamenta "a priori” pretensões individuais diretas de qualquer tipo, embora possa ser de extraordinária importância para interpretar os direitos fundamentais que, como direitos derivados de participação, possam justificar tais demandas (HESSE, 2009, p. 50).

Porém, em que pesem os debates sobre a possibilidade de alegação da "reserva do possível" para justificar as omissões em termos de efetivação de direitos sociais, há de se ter claro que, no que tange ao cumprimento do "mínimo vital", resta inequívoca a inadmissibilidade de o Estado furtar-se à concretização de um dado direito fundamental social, sob pena de esvaziamento de seu conteúdo e de desrespeito ao princípio da dignidade da pessoa humana.

Essa premissa torna-se robusta quando se percebe que a Constituição brasileira arrola uma série de direitos sociais, conformando-os como direitos fundamentais, dentre os quais se destacam a educação, a saúde, o trabalho, a moradia, o lazer, a segurança, a previdência social, a proteção à maternidade e à infância e a assistência aos desamparados (arts. $6^{\circ}$ a 11).

Impõe, assim, especialmente em períodos de "crises econômicas", reafirmar a imprescindibilidade da realização dos direitos sociais, para que não se admita o esvaziamento do conteúdo solidarístico dessa espécie de direitos humanos, com destaque para a educação, cuja efetividade é condição para que o indivíduo possa participar ativamente da sociedade e, com isso, possa exercer plenamente a cidadania.

\section{JUDICIALIZAÇÃO DO DIREITO SOCIAL À EDUCAÇÃO: DIREITO SUBJETIVO E POLÍTICA PÚBLICA}

A educação, importante ferramenta de emancipação do humano, é consagrada, enquanto direito fundamental, no art. $6^{\circ}$ da Constituição Federal de 1988.

Por outro lado, no art. 205 da Lei Maior, a educação é concebida como direito necessário ao exercício da cidadania, porque propicia o pleno desenvolvimento do indivíduo e sua qualificação para o trabalho.

A concretização do direito à educação deve, assim, se dar preferencialmente por meio da implementação de políticas públicas, entendidas como sendo um conjunto de ações 
destinado a movimentar a máquina estatal para fins de concretização dos direitos fundamentais sociais. Em outras palavras, as políticas públicas representam, basicamente, "a eficácia social do direito do cidadão a obter prestações positivas do Estado" (FRISCHEISEN, 2000, p. 76).

Nesse contexto, cabe precipuamente aos Poderes Legislativo e Executivo elegerem e viabilizarem estratégias de concretização das políticas públicas educacionais, a fim de que seja concretizado o direito fundamental à educação.

Ocorre, porém, que nem sempre o poder público cumpre voluntariamente seu papel, especialmente quando se trata do cumprimento de direitos prestacionais, a exemplo do direito à educação. Ou seja, embora garantido constitucionalmente, o direito à educação nem sempre está acessível ao cidadão, seja pela ausência de políticas públicas que assegurem a sua fruição, seja pela ineficiência da ação estatal na garantia desse importante direito.

Destarte, se, por um lado, as políticas públicas educacionais se submetem à atuação discricionária dos órgãos competentes, também é igualmente verdadeiro que, de outro lado, elas estão vinculadas aos princípios fundamentais do Estado Democrático de Direito, que traz consigo a exigência de concretude dos direitos fundamentais.

Nessa perspectiva, o conceito de discricionariedade não pode corresponder à possibilidade de omissão pelo Poder Público, que passaria a estar avalizado a agir segundo seu bel prazer na implementação de políticas públicas. Ao contrário: a partir das lições de Celso Antônio Bandeira de Mello (2007, p. 32-33), é possível concluir que o administrador está, "nos casos de discricionariedade, perante o dever jurídico de praticar, não qualquer ato dentre os comportados pela regra, mas, única e exclusivamente aquele que atenda com absoluta perfeição à finalidade da lei”. O mesmo entendimento dever ser aplicado também ao legislador.

Por outro lado, conquanto seja precipuamente de competência dos Poderes Executivo e Legislativo a implementação dessas políticas públicas, cada vez mais se torna importante a atuação do Ministério Público, cujo perfil institucional está contemplado no art. 127, "caput”, da Constituição Federal de 1988, e do Poder Judiciário no controle das políticas públicas, sobretudo quando sua implementação depender da discricionariedade do poder público.

Cumpre aqui lembrar, sem a pretensão de se aprofundar no tema, que há muito se encontra superada a alegação, pelo poder público, de violação ao Princípio da Separação dos Poderes, como justificativa para descumprimento de medidas concernentes ao pleno exercício ao direito à educação, porquanto a judicialização das políticas públicas educacionais 
representa a garantia ao indivíduo de ter concretizado o seu direito fundamental à educação, dada a omissão do Poder responsável por sua efetividade. Em outras palavras, a justiciabilidade do direito à educação consiste em valiosa estratégia de efetivação, ainda que subsidiária, desse importante direito humano fundamental.

A propósito, o tema encontra amparo na jurisprudência do Supremo Tribunal Federal consoante se apreende do paradigmático voto relatado pelo Excelentíssimo Ministro Celso de Mello, nos termos da ementa a seguir aduzida:

RECURSO EXTRAORDINÁRIO - CRIANÇA DE ATÉ SEIS ANOS DE IDADE - ATENDIMENTO EM CRECHE E EM PRÉ-ESCOLA EDUCAÇÃO INFANTIL - DIREITO ASSEGURADO PELO PRÓPRIO TEXTO CONSTITUCIONAL (CF, ART. 208, IV) - COMPREENSÃO GLOBAL DO DIREITO CONSTITUCIONAL À EDUCAÇÃO - DEVER JURÍDICO CUJA EXECUÇÃO SE IMPÕE AO PODER PÚBLICO, NOTADAMENTE AO MUNICÍPIO (CF, ART. 211, § $2^{\circ}$ ) - RECURSO IMPROVIDO.

- A educação infantil representa prerrogativa constitucional indisponível, que, deferida às crianças, a estas assegura, para efeito de seu desenvolvimento integral, e como primeira etapa do processo de educação básica, o atendimento em creche e o acesso à pré-escola (CF, art. 208, IV).

- Essa prerrogativa jurídica, em consequência, impõe, ao Estado, por efeito da alta significação social de que se reveste a educação infantil, a obrigação constitucional de criar condições objetivas que possibilitem, de maneira concreta, em favor das "crianças de zero a seis anos de idade" (CF, art. 208, IV), o efetivo acesso e atendimento em creches e unidades de pré-escola, sob pena de configurar-se inaceitável omissão governamental, apta a frustrar, injustamente, por inércia, o integral adimplemento, pelo Poder Público, de prestação estatal que lhe impôs o próprio texto da Constituição Federal.

- A educação infantil, por qualificar-se como direito fundamental de toda criança, não se expõe, em seu processo de concretização, a avaliações meramente discricionárias da Administração Pública, nem se subordina a razões de puro pragmatismo governamental.

- Os Municípios - que atuarão, prioritariamente, no ensino fundamental e na educação infantil $\left(\mathrm{CF}\right.$, art. $\left.211, \S 2^{\circ}\right)$ - não poderão demitir-se do mandato constitucional, juridicamente vinculante, que lhes foi outorgado pelo art. 208, IV, da Lei Fundamental da República, e que representa fator de limitação da discricionariedade político-administrativa dos entes municipais, cujas opções, tratando-se do atendimento das crianças em creche $(\mathrm{CF}$, art. 208, IV), não podem ser exercidas de modo a comprometer, com apoio em juízo de simples conveniência ou de mera oportunidade, a eficácia desse direito básico de índole social.

- Embora resida, primariamente, nos Poderes Legislativo e Executivo, a prerrogativa de formular e executar políticas públicas, revela-se possível, no entanto, ao Poder Judiciário, determinar, ainda que em bases excepcionais, especialmente nas hipóteses de políticas públicas definidas pela própria Constituição, sejam estas implementadas pelos órgãos estatais inadimplentes, cuja omissão - por importar em descumprimento dos encargos político-jurídicos que sobre eles incidem em caráter mandatório mostra-se apta a comprometer a eficácia e a integridade de direitos sociais e 
culturais impregnados de estatura constitucional. A questão pertinente à "reserva do possível". Doutrina. (BRASIL, 2006)

No caso, ao concretizar o direito à educação em creche e pré-escola (em observância ao art. 208, IV da Constituição Federal), o Poder Judiciário está viabilizando a garantia do piso mínimo de dignidade, imprescindível ao respeito da dignidade da pessoa humana.

E, diante da omissão estatal, revela-se mais apropriada a utilização dos instrumentos de tutela coletiva para se exigir a reparação da violação ao direito à educação, por ser esta uma opção mais universalizante, ao permitir uma melhor implementação de políticas públicas e de distribuição de justiça social.

Isso não implica dizer que o individuo não possa também se valer da tutela individual, invocando seu direito subjetivo à educação, notadamente quando, diante da omissão estatal, a reparação coletiva não tenha ainda sido adotada ou mesmo se revelar insuficiente.

Por esta linha de intelecção, e conquanto não haja uniformização acerca do tema, impõe considerar que somente poderá ser qualificado como subjetivo, em linhas gerais, o direito que possa ser exigido em Juízo pelo seu titular.

Segundo Cristina Queiroz (2006, p. 143), “os direitos fundamentais sociais são 'direitos subjetivos' sempre que possam ser feitos valer a justiça, isto é, desde que possam ser accionados judicialmente a requerimento do respectivo titular".

Desta feita, revela-se determinante à caracterização de um direito subjetivo (tomado no sentido técnico), a possibilidade da respectiva coercibilidade judicial, o que se insere no campo da "justiciabilidade" dos direitos fundamentais sociais, que, segundo palavras de Cristina Queiroz (2006, p. 148), consiste na

\begin{abstract}
possibilidade de o titular do direito reclamar perante um juiz ou tribunal o cumprimento das obrigações que derivam desse direito. Neste sentido, ser titular de um direito subjetivo significa deter um poder jurídico reconhecido pelo direito objetivo, isto é, deter o poder de participar na criação de uma norma jurídica individual por intermédio de uma acção específica em justiça, designadamente através de reclamação ou queixa.
\end{abstract}

A par disso, impende reconhecer que direitos humanos básicos, a exemplo da educação, não podem ser tratados como direitos consagrados em normas jurídicas programáticas, para que sejam tomados como "direitos prestacionais de natureza subjetiva" naquilo que eles contêm de eminentemente "pessoal", isto é, no que se refere diretamente à 
"dignidade da pessoa humana" na sua dupla dimensão "individual" e "social", como "ser socialmente integrado" (QUEIROZ, 2006, p. 155).

Isso porque a Constituição Federal não deve ser tomada como simples ideário; nem mera expressão de anseios, de aspirações, de propósitos, mas sim como norma transformadora da realidade social, que converte anseios e aspirações em regras impositivas, em comandos, em preceitos obrigatórios para todos os órgãos do Poder e para os cidadãos (MELLO, 2010, p. $11)$.

Ademais, afora a consagração do direto à educação no rol dos direitos sociais (art. $6^{\circ}$, “caput”, da Constituição Federal de 1988), o art. 206 da Lei Maior optou pelo conceito de educação que visa à formação integral do indivíduo, dispondo que "a educação, direito de todos e dever do Estado e da família, será promovida e incentivada com a colaboração da sociedade, visando ao pleno desenvolvimento da pessoa, seu preparo para o exercício da cidadania e sua qualificação para o trabalho" (BRASIL, 1988), o que realça o importante papel da educação para a garantia da inserção social do ser humano.

Não é por outra razão que José Celso de Mello Filho (1986, p. 533) já asseverava que a educação

objetiva propiciar a formação necessária ao desenvolvimento das aptidões, das potencialidades e da personalidade do educando. O processo educacional tem por meta: (a) qualificar o educando para o trabalho; e (b) prepará-lo para o exercício consciente da cidadania. $\mathrm{O}$ acesso à educação é uma das formas de realização concreta do ideal democrático.

Ainda, é no art. 208, $\S 1^{\circ}$, da Constituição Federal que a educação é reconhecida como direito público subjetivo, relativamente ao acesso ao ensino obrigatório e gratuito. Em outras palavras, relativamente ao ensino obrigatório e gratuito pode o Estado ser coagido a prestá-lo quando restar omisso em seu dever.

De outro lado, conquanto as demais previsões constantes dos incisos do art. 208 não tenham sido expressamente consignadas como direito público subjetivo, a exemplo da progressiva universalização do ensino médio gratuito; do atendimento educacional especializado aos portadores de deficiência, preferencialmente na rede regular de ensino; da educação infantil, em creche e pré-escola, às crianças até 5 (cinco) anos de idade; do acesso aos níveis mais elevados do ensino, da pesquisa e da criação artística, segundo a capacidade de cada um; da oferta de ensino noturno regular, adequado às condições do educando e do atendimento ao educando, em todas as etapas da educação básica, por meio de programas 
suplementares de material didático-escolar, transporte, alimentação e assistência à saúde, não há dúvidas de que todas elas também consistem em autênticos direitos subjetivos, na esteira da jurisprudência do E. Supremo Tribunal Federal, conforme se observa do seguinte julgado:

\begin{abstract}
É preciso assinalar, neste ponto, por relevante, que o direito à educação que representa prerrogativa constitucional deferida a todos (CF, art. 205), notadamente às crianças (CF, arts. 208, IV, e 227, "caput") - qualifica-se como um dos direitos sociais mais expressivos, subsumindo-se à noção dos direitos de segunda geração (RTJ 164/158-161), cujo adimplemento impõe, ao Poder Público, a satisfação de um dever de prestação positiva, consistente num "facere", pois o Estado dele só se desincumbirá criando condições objetivas que propiciem, aos titulares desse mesmo direito, o acesso pleno ao sistema educacional, inclusive ao atendimento, em creche e pré-escola, "às crianças até 5 (cinco) anos de idade" (CF, art. 208, IV, na redação dada pela $\underline{\left.\mathrm{EC} \mathrm{n}^{\circ} 53 / 2006\right)}$ - destaque nosso - (BRASIL, 2011).
\end{abstract}

Analisada a justiciabilidade do direito à educação, tanto na perspectiva da implementação de políticas públicas pelos órgãos responsáveis, seja voluntariamente ou coercitivamente por meio da tutela coletiva, quanto na invocação do direito subjetivo, resta analisar os principais desafios para que esse importante direito humano fundamental possa ter plena efetividade no Brasil, que não apenas na óptica do seu acesso e universalização.

\title{
4 DESAFIOS À EFETIVIDADE DO DIREITO À EDUCAÇÃO
}

No âmbito na proteção global especial dos direitos humanos, a Convenção Internacional sobre os Direitos da Criança (1989), aprovada pela ONU em 20/11/89, e assinada pelo Brasil em 26/01/90 e aprovada pelo Decreto Legislativo no 28, de 14/09/90, reforça a doutrina da Proteção Integral encampada no ordenamento jurídico brasileiro pela Constituição Federal (art. 227) e pela Lei $n^{\circ}$ Lei 8.069/1990 (Estatuto da Criança e do Adolescente - ECA).

Os referidos instrumentos normativos, quando interpretados de forma sistemática, "traduzem uma visão integral dos direitos humanos das crianças e dos adolescentes, contemplando a indivisibilidade destes direitos, sua implementação recíproca e a igual importância de todos os direitos, sejam civis, políticos, sociais, econômicos ou culturais" (PIOVESAN, 2009, p. 295).

Nessa perspectiva, a Constituição Federal, em seu art. 205, explicita claramente que “a educação, direito de todos e dever do Estado e da família, será promovida e incentivada 
com a colaboração da sociedade, visando ao pleno desenvolvimento da pessoa, seu preparo para o exercício da cidadania e sua qualificação para o trabalho" (BRASIL, 1988).

Por sua vez, o Estatuto da Criança e do Adolescente dispõe, em seu art. 53, que "a criança e o adolescente têm direito à educação, visando ao pleno desenvolvimento de sua pessoa, preparo para o exercício da cidadania e qualificação para o trabalho, (...)” (ECA, 1990).

Assim, à luz dos dispositivos referidos, revela-se inegável a direta correlação entre a garantia do direito à educação e o pleno exercício da cidadania, entendida esta como o "direito a ter direito", segundo a perspectiva de Hannah Arendt, trabalhada por Celso Lafer (LAFER, 1988, p. 146-166).

Ocorre, porém, que é preciso reconhecer que o mero acesso à educação formal não é garantia de efetividade desse importante direito humano. Em outros termos, a universalidade da educação, conquanto deva ser priorizada pelo Estado, não é, por si só, nem de longe, suficiente para garantir o pleno desenvolvimento da pessoa humana, com vistas ao preparo para o exercício da cidadania e à qualificação profissional.

Isso porque a formação integral do indivíduo exige, para que sejam assegurados os preceitos da Constituição Federal, da Convenção Internacional sobre os Direitos da Criança e do Estatuto da Criança e do Adolescente - ECA, que a educação prestada seja de qualidade e que sejam adotados mecanismos que incentivem a permanência da criança e do adolescente nas escolas, o que também guarda relação direta com o reconhecimento da mutabilidade dos parâmetros para a garantia de uma vida, conforme já explanado.

Portanto, a universalização do direito à educação precisa ser acompanhada da sua boa qualidade, sem o que a formação do indivíduo restará ainda assim prejudicada e esse direito humano fundamental não restará plenamente efetivado.

A propósito, segundo a Organização das Nações Unidas para a Educação, a Ciência e a Cultura (Unesco), dentre as seis metas assumidas pelo Brasil no Marco de Ação de Dakar, Educação para Todos, estabelecidas no ano de 2000 por 164 países, apenas duas foram cumpridas pelo país, ou seja, a que consistia na meta de universalizar o acesso à educação primária do $1^{\circ}$ ao $5^{\circ}$ ano do ensino fundamental e a referente à inclusão de meninos e meninas na escola, independentemente do gênero. Segundo noticiado, em 2015, pela UNESCO, "reduzir o analfabetismo dos adultos, garantir educação de qualidade aos jovens e as crianças com menos de 5 anos de idade continuam sendo desafios para o país (UNESCO, 2015). 
Sendo assim, para além dos reconhecidos avanços do Brasil no âmbito educacional, sobretudo após a ordem constitucional de 1988, é imperioso reconhecer que muito ainda precisa ser feito, especialmente no que concerne à melhoria da qualidade de ensino para todos os indivíduos, especialmente para as camadas sociais menos favorecidas, seja porque este segmento populacional não possui condições de subsidiar os estudos em escolas particulares (reconhecidamente superiores à maioria das escolas públicas de nível fundamental), seja porque essa população é praticamente impedida de competir, em pé de igualdade, com os alunos de ensino particular a uma vaga nas universidades públicas, dada a defasagem na formação desses alunos.

Sem a adoção dessa perspectiva, é impossível garantir a plena efetivação do direito à educação se a sua implementação vier desprovida de qualidade, o que pode até mesmo dar ensejo à busca do Poder Judiciário para a consecução dessa finalidade, dadas as previsões constitucional e infraconstitucional, que garantem à criança e ao adolescente o direito à educação voltado ao seu pleno desenvolvimento, ao preparo para o exercício da cidadania e à qualificação para o trabalho.

Sem isso, e por mais utópico que possa parecer ser, cada vez mais se torna distante o ideal de educação preconizado por Jean-Jacques Rousseau, em 1792, segundo o qual o sistema educacional deve formar o cidadão, partícipe da vontade geral, responsável pela formação do Estado, o qual há de viver numa nova sociedade, moldada pela moral e pela justiça. A educação preconizada por Rousseau consistiria, portanto, na única forma de o homem conquistar o direito de liberdade e o de igualdade que teriam sido perdidos, estando ela voltada para a felicidade humana, com o resgate da pureza do homem, possibilitando-se, com isso, a criação de um homem novo, capaz de gerir o Estado onde imperaria a vontade geral (ROUSSEAU, apud SIFUENTES, 2009, p. 31-32.)

\section{CONCLUSÕES}

A educação é um direito fundamental por excelência, embora a realidade brasileira demonstre que sua efetivação está muito aquém do esperado, notadamente se considerado o momento atual, em que a retórica governamental educacional não vem acompanhada de estratégias de positivação que de fato façam da educação uma prioridade como política de governo. 
Inegavelmente, a educação está intrinsecamente ligada à dignidade da pessoa humana, tomada esta como fundamento da República Federativa do Brasil e princípio informador de toda a ordem jurídica.

O direito fundamental à educação constitui pressuposto legítimo ao pleno exercício da cidadania, por possibilitar a efetiva participação do indivíduo na tomada de decisões dos entes estatais em prol da coletividade.

Não é crível conceber que o indivíduo apartado do processo educacional possa desenvolver no contexto social todas as suas potencialidades, especialmente se considerado o caráter instrumental dos direitos sociais.

No Brasil, a realidade é marcada por desafios relacionados à efetividade do direito à educação, uma vez que são bastante expressivos os índices de analfabetismo existentes no país e o descumprimento de metas educacionais assumidas pelo Estado brasileiro perante organismos internacionais.

Por mais que a educação seja tema recorrente de palestras, artigos e seminários científicos no país, sempre será necessário reafirmar sua fundamentalidade e repensar as estratégias de positivação desse direito humano fundamental.

A efetivação do direito à educação passa, de um lado, pela eleição governamental de políticas públicas adequadas e, de outro lado, pela utilização de instrumentos jurídicos aptos à sua concretização, seja individualmente, por meio da proteção judicial do direito subjetivo, seja coletivamente, por intermédio da implementação das políticas públicas.

A justiciabilidade dos direitos fundamentais, em especial do direito à educação, contribui de forma concreta para a realização dos direitos sociais no contexto brasileiro, identificando-se a dignidade da pessoa humana como o parâmetro mais apropriado ao Magistrado para a garantia desses direitos fundamentais, sem se perder de vista, ainda, o caráter rebus sic stantibus do "mínimo de existência condigna".

No que se refere ao "mínimo existencial", em face da diretriz estabelecida pela aplicação do princípio da dignidade da pessoa humana, inexiste margem para a escusa por parte do Poder Público em concretizar o direito fundamental social relativo à educação, não sendo aplicável, no caso, a invocação da "reserva do possível" ou a alegação de ofensa à separação de poderes.

Em conclusão, tem-se que o direito fundamental à educação, em regra, caso não atendido e implementado voluntariamente pelo Estado, pode ser efetivado por meio de medidas judiciais tendentes à sua realização, seja por meio de ações judiciais individuais, seja 
por intermédio de medidas judiciais coletivas, preservando-se, assim, o princípio fundamental da dignidade da pessoa humana contemplado no inciso III do art. $1^{\circ}$ da Constituição da República Federativa do Brasil, cujo conteúdo, reconhecidamente mutável, deve propiciar ao indivíduo maior inserção social e condições para o exercício pleno da cidadania, o que não se faz realizável sem a melhoria da qualidade da educação prestada em nosso país.

\section{REFERÊNCIAS}

BRASIL. Constituição da República Federativa do Brasil de 1988. Disponível em: http://www.planalto.gov.br/ccivil_03/Constituicao/ConstituicaoCompilado.htm. Acesso em 25 set. 2016.

. Lei $\mathrm{n}^{\mathrm{o}}$ 8.069, de 13 de julho de 1990. Disponível em: http://www.planalto.gov.br/ccivil_03/leis/L8069.htm. Acesso em 25 set. 2016.

. Superior Tribunal de Justiça. Recurso Especial n. 1.185.474-SC. Ministro Humberto Martins. Brasília: DJe, 29 abr. 2010.

Supremo Tribunal Federal. Agravo Regimental no Recurso Extraordinário n 410.715/SP. Ministro Relator Celso de Mello. Brasília: DJ, 3 fev. 2006.

- Supremo Tribunal Federal. Agravo de Instrumento no Recurso Extraordinário n. 639.337-SP. Ministro Relator Celso de Mello. Brasília: DJe, 28 jun. 2011.

BUCCI, Maria Paula Dallari. O conceito de política pública em direito. In BUCCI, Maria Paula Dallari (Org.). Políticas públicas: reflexões sobre o conceito jurídico. São Paulo: Saraiva, 2006, p. 1-49.

CANOTILHO. Estudos sobre direitos fundamentais. $1^{\mathrm{a}}$ ed. brasileira, $2^{\mathrm{a}}$ ed. portuguesa. São Paulo: Revista dos Tribunais; Portugal: Coimbra Editora, 2008.

COMPARATO, Fábio Konder. A afirmação histórica dos direitos humanos. $7^{\mathrm{a}}$ ed. São Paulo: Saraiva, 2010. 
FRISCHEISEN, Luíza Cristina Fonseca. Políticas públicas: a responsabilidade do administrador e o Ministério Público. São Paulo: Max Limonad, 2000.

HESSE, Konrad. Temas fundamentais do direito constitucional. Textos selecionados e traduzidos por Carlos dos Santos Almeida, Gilmar Ferreira Mendes e Inocêncio Mártires Coelho. São Paulo: Saraiva, 2009.

LAFER, Celso. A reconstrução dos direitos humanos: um diálogo com o pensamento de Hannah Arendt. $2^{a}$ ed. São Paulo: Companhia das Letras, 1988.

MEIRELES, Cecília. Crônicas de educação 1 (obra em prosa). Apresentação e planejamento editorial de Leodegário A. de Azevedo Filho. Rio de Janeiro: Nova Fronteira Fundação Biblioteca Nacional, 2001.

MELlO FILHO, José Celso de. Constituição federal anotada. $2^{\mathrm{a}}$ ed. São Paulo: Saraiva, 1986.

MELLO, Celso Antônio Bandeira de. Discricionariedade e controle jurisdicional. $2^{\mathrm{a}}$ ed. São Paulo: Malheiros, 2007.

Eficácia das normas constitucionais e direitos sociais. $1^{\mathrm{a}}$ ed. São Paulo: Malheiros, 2010.

NUNES JÚNIOR, Vidal Serrano. A cidadania social na Constituição de 1988: estratégias de positivação e exigibilidade judicial dos direitos sociais. São Paulo: Verbatim, 2009, p. 70.

ONU. Relatório do Desenvolvimento Humano 2015. Disponível em <http://hdr.undp.org/sites/default/files/hdr_2015_report_pt.pdf>. Acesso em 19 set. 2016.

PIOVESAN, Flávia. Direitos humanos e o direito constitucional internacional. $14^{\mathrm{a}}$ ed. São Paulo: Saraiva, 2011. . Temas de direitos humanos. $3^{\mathrm{a}}$ ed. São Paulo: Saraiva, 2009. 
QUEIROZ, Cristina. Direitos fundamentais sociais: funções, âmbito, conteúdo, questões interpretativas e problemas de justiciabilidade. Coimbra: Coimbra Editora, 2006.

SARLET, Ingo Wolfgang. Dignidade da pessoa humana e direitos fundamentais na Constituição Federal de 1988. $9^{\text {a }}$ ed. Porto Alegre: Livraria do Advogado, 2011.

Direitos fundamentais sociais, "mínimo existencial" e direito privado: breves notas sobre alguns aspectos da possível eficácia dos direitos sociais nas relações entre particulares. In SARMENTO, Daniel; GALDINO, Flávio (Orgs.). Direitos fundamentais: estudos em homenagem ao professor Ricardo Lobo Torres. Rio de Janeiro: Renovar, 2006.

SIFUENTES, Mônica. Direito fundamental à educação: a aplicabilidade dos dispositivos constitucionais. Porto Alegre: Núria Fabris Ed., 2009.

SILVA, José Afonso da. Curso de direito constitucional positivo. $19^{\mathrm{a}}$ ed. rev. e atual. São Paulo: Malheiros, 2001.

UNESCO. Brasil cumpriu duas das seis metas da Educação estabelecidas em 2000. Disponível em: <http://agenciabrasil.ebc.com.br/educacao/noticia/2015-04/unesco-brasilcumpriu-duas-das-seis-metas-da-educacao-estabelecidas-em-2000>. Acesso em 25 set. 2016. 